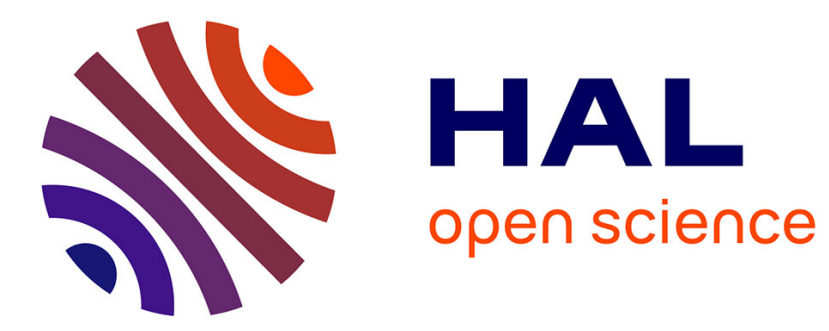

\title{
Spectral Analysis of the Response of Coarse Granular Material to Dynamic Penetration Test Modelled with DEM
}

Quoc Anh Tran, Bastien Chevalier, Pierre Breul

\section{- To cite this version:}

Quoc Anh Tran, Bastien Chevalier, Pierre Breul. Spectral Analysis of the Response of Coarse Granular Material to Dynamic Penetration Test Modelled with DEM. International Journal of Geosynthetics and Ground Engineering, 2018, 4, pp.22. 10.1007/s40891-018-0139-5 . hal-01885925

\section{HAL Id: hal-01885925 \\ https://hal.uca.fr/hal-01885925}

Submitted on 17 Nov 2020

HAL is a multi-disciplinary open access archive for the deposit and dissemination of scientific research documents, whether they are published or not. The documents may come from teaching and research institutions in France or abroad, or from public or private research centers.
L'archive ouverte pluridisciplinaire HAL, est destinée au dépôt et à la diffusion de documents scientifiques de niveau recherche, publiés ou non, émanant des établissements d'enseignement et de recherche français ou étrangers, des laboratoires publics ou privés. 
1 Spectral analysis of the response of coarse granular material

2

3

4

5

6

7 Université Clermont Auvergne, CNRS, SIGMA Clermont, Institut Pascal, F-63000

8 CLERMONT-FERRAND, FRANCE

9 Tel. $+33(0) 4.73 .40 .75 .23$

$10 \quad$ Fax. $+33(0) 4.73 .40 .74 .94$

11

12

13

14

15

16

17

18

19

20

21

22

\author{
Quoc Anh Tran, Bastien Chevalier and Pierre Breul
}

Correspondence to bastien.chevalier@uca.fr
1 (1) 3 4 5 6 7 18 9 


\section{Abstract}

Dynamic penetration tests are often used to determine the strength properties of surface soils. The paper presents a study on the use of spectral analysis on dynamic cone penetration tests results, modelled with Discrete Element Method. This method is applied to assess the effect of the variation of the grain size distribution of the soil on test results. A two-dimensional discrete model is used to reproduce cone penetration tests in dynamic conditions: the tip of the penetrometer is driven in the material by successive impacts of a hammer on the penetrometer. For each impact of the hammer, a curve of the load applied by the tip on the soil is obtained versus the penetration distance of the tip. The curves of the load vs. penetration traditionally used to calculate the tip resistance of the soil are analyzed with Discrete Fourier transform in order to investigate curve's shape. The effect of the variation of the grain size distribution of the soil on these curves is investigated, i.e. average particle diameter and span of particle size distribution. It was found out that the grain size distribution influences tip resistance but also the shape and oscillation modes of the curve of the stress-penetration curve. Based on these indicators, the exploitation of the load-displacement curve obtained with dynamic penetration tests could be enlarged to determine other properties of the soils.

Keywords: dynamic cone penetration, discrete element method, granular material, particle size distribution, Discrete Fourier Transform.

\section{Introduction}

In the practice of geotechnical engineering, the use of in situ testing is widespread. Among existing testing techniques, lightweight dynamic penetration testing device such as Panda penetrometer is used to characterize mechanical properties of surface soils [1,2]. Based on recent technological improvements, this device is able to record the curve of the tip stress or tip force versus the tip penetration distance for each impact of the hammer on the penetrometer $[3,4]$. This curve, referred to as load-penetration curve, provides information on dynamic tip resistance but also on additional mechanical parameters involved during the driving of the tip $[3,5,6]$. Cone penetration test is a blind testing technique, because there is no sampling of the different layers of soils that are cut across. It would be very interesting to be able to get information about the nature of the soils, from the actual measurements recorded by the device. The present paper proposes to study the effect of the particle size distribution on the load vs. penetration distance measured at the tip. Numerical modelling using Discrete Element Method 
was chosen so that we have a strict control on the parameters of the particle size distribution (PSD).

The numerical model of penetration tests using Discrete Element Method (DEM) used to reproduce the penetration tests in dynamic conditions is the same model as the one presented in [7]. Many authors have modeled cone penetration tests before with DEM in 2D [8-15] and in 3D [3,16-20]. However, most of them modelled the penetration in static conditions, i.e. with a constant velocity of the tip, and very few focused on penetration tests in dynamic conditions, i.e. with impacts $[6,7,19]$.

At the macroscopic scale, the tip resistance quantifies the mechanical response of the granular material to the driving of the tip (Fig.1). At the scale of the contacts or of the particles, the shapes of the load-penetration curves are analyzed in terms of both frequency and amplitude of signal oscillation by using Discrete Fourier Transform (DFT). Figure 2 shows an example of the load penetration curve. The objective of the study is to evaluate the effect of the PSD on the load-penetration curves, based on DFT analysis. Two parameters were tested: the average particle diameter, $D_{50}$ and the span of the PSD given as the ratio of maximal particle diameter $D_{\max }$ to minimal diameter $D_{\min }$.

At first, we will present the numerical model and parameters used to reproduce the dynamic penetration test as well as the method used to analyze the load-penetration curve with DFT. Finally, the influence of the particle size distribution is discussed.

\section{Numerical model}

Discrete Element Method in two dimensions is used with Itasca software PFC ${ }^{2 D}$ [21]. Dense assemblies of disks are generated without gravity and without friction in a container of $0.60 \mathrm{~m}$ in width and of $0.45 \mathrm{~m}$ in height (Fig.3). The lateral walls of the container are fixed. A study of boundary conditions with different sample sizes on this numerical model was conducted by Tran et al. [14] and revealed that for a container width larger than $0.60 \mathrm{~m}$, there is no effect of the lateral walls on the tip resistance anymore. A linear contact model is used along with a Coulomb friction criterion after the generation process. The normal contact stiffness of $1.25 \times 10^{8} \mathrm{~N} / \mathrm{m}$ is chosen in order to assess the assumption of rigid particles during penetration tests [22-24]. The tangential contact stiffness has been set to 0.75 of normal contact stiffness.

The samples are generated without friction and without gravity in order to reach a random close packing volume fraction, corresponding to the minimal void ratio of the considered PSD. After 
sample generation, gravity is applied to the system as well as a confining vertical stress of $40 \mathrm{kPa}$. The confining stress is applied on the top face of the container to simulate an overlaying layer of material and to prevent the effects of free surface to be observed [1].

The penetration tests were performed with a frictionless rod of width $D_{\text {rod }}=14 \mathrm{~mm}$ linked to a tip of width $D_{\text {tip }}=16 \mathrm{~mm}$ at its bottom edge which has a friction coefficient $\mu_{\text {tip }}$ of 0.3 [19]. First, the rod is driven with constant velocity until a depth of $0.15 \mathrm{~m}$ is reached inside the granular material. Then, the rod is released and stabilized under its own weight. Finally, series of five successive impacts are produced in the sample with a hammer represented by an additional disk hitting the top of the rod (Fig.3). The mass of the impacting cylinder is equal to the rod mass. The impacting velocity at the impact is equal to $1,25 \mathrm{~m} \cdot \mathrm{s}^{-1}$ in order to obtain an average penetration distance that is representative of experimental tests. The description of the model and the effect of the impact velocity are addressed by Tran et al. in [7]. Table 1 summarizes the main parameters of the model.

Table 2 summarizes the parameters of the five granular materials studied, with two types of PSD. The first distribution type (I) keeps constant the ratio between maximal and minimal particle diameters $D_{\max } / D_{\min }=2$, and particle number varies from 10000 to 160000 making the average diameter $D_{50}$ varying (Fig.4 a). The second distribution type (II) keeps constant maximal diameter $D_{\max }=7.02 \mathrm{~mm}$ and the ratio between maximal and minimal particle diameters $D_{\max } / D_{\min }$ varies from 2 to 10 (Fig.4 b). All the samples were tested with their maximal volume fraction $\left(\phi_{\max }\right)$ and with a particle friction coefficient equal to 1.0.

For each type of granular material, the testing process was repeated on three different samples corresponding to the same sample conditions but with different initial particle arrangements.

The following section explains how the load-penetration curves obtained from dynamic cone penetration tests were analyzed in the frequency domain by using $D F T$.

\section{Investigation of load - penetration curve}

\subsection{Macroscopic exploitation for the tip resistance}

Tip force $F_{d}$ is defined as the vertical component of the force applied by the granular material on the tip as it drives in the granular with a penetration distance $s$. Figure 5 shows examples of load-penetration curves $F_{d}=f(s)$ obtained for 3 impacts with the numerical model on the material $B$. The response obtained with the model is similar to the one classically obtained experimentally [4]. 
116 At the end of the driving process, the tip reaches a final position corresponding to a residual 117 penetration distance $s_{\text {res }}$. We can notice that there is a difference between the maximal 118 penetration distance $s_{\max }$ and the final residual penetration distance $s_{\text {res }}$ (Fig.5). However, the mechanical work of the tip force between these two positions is negligible due to the value of the tip force between these two positions. Consequently, the dynamic tip resistance $R_{d}$ of the 121 granular material for one impact was calculated as the average tip force $F_{d}$ for penetration 122 distance between 0 and $s_{\max }$ :

$$
\mathrm{R}_{\mathrm{d}}=\frac{1}{s_{\max }} \int_{t=0}^{t_{s_{\max }}} F_{d}(\mathrm{t}) \mathrm{ds}(\mathrm{t})
$$

123 with: $t$ the time; $t_{\text {smax }}$ the time when penetration distance is maximal and equal to $s_{\max }$. Then, $\left\langle R_{d}\right\rangle$ is the average value of dynamic tip resistances obtained for the five impacts and for the three samples.

\subsection{Frequency analysis using Discrete Fourier Transform}

127 Each load-penetration curve presents variations - i.e. oscillations, peaks - observed between the time of the impact and the time when the system stabilizes again (Fig.5). As the properties of the granular material change, the shape and size of these variations change too. Consequently, the load-penetration curve can provide not only the tip resistance of granular media but also

131 information on the granular material properties.

132 Fourier transformation provides a powerful way for study discrete data acquisition in the 133 frequency domain. It allows to decompose a signal into the frequencies that make it up. Discrete 134 Fourier Transform (DFT) changes the $N$ "temporal" points $y_{n}(x)$ in to $N$ "frequency" points $Y_{k}$ 135 and inverse DFT the other way around by using the following equations:

$$
\begin{aligned}
\mathrm{Y}_{\mathrm{k}} & =\sum_{n=0}^{N-1} y_{n} e^{-2 \pi i n k / N} \\
\mathrm{y}_{\mathrm{n}} & =\sum_{k=0}^{N-1} Y_{k} e^{2 \pi i n k / N}
\end{aligned}
$$

136 with: $y_{n}$ the original function, $Y_{k}$ the transformed function and $N$-points DFT.

137 The DFT bins $\left(f_{k}\right)$ represent frequencies in the discrete Fourier transform that are spaced at 138 intervals of $\Delta f_{k}=F_{s} / N$, where $F_{s}$ is the sample rate equal to $1 / \Delta x$, with $\Delta x$ the recording interval. 139 All of load-penetration curve have been analyzed in frequency domain with $F_{\mathrm{s}}=10^{5}\left[\mathrm{~m}^{-1}\right]$ and 140 frequency resolution $\Delta f_{k}=F_{s} / N=0.1$. The equation of inverse $D F T$ can be computed by the 141 following formula: 


$$
\mathrm{y}_{\mathrm{n}}=\sum_{k=0}^{N-1} A_{k} \cos \left(2 \pi f_{k} x+\varphi\right)
$$

142 with: $f_{k}$ the $k^{\text {th }}$ frequency, $A_{k}$ the associated amplitude and $\varphi$ the phase of $Y_{k}$ with

$$
\varphi=\tan ^{-1}(\operatorname{Img}(Y k) / \operatorname{Real}(Y k))
$$

143 In order to obtain a stabilized and accurate amplitude spectrum, it is necessary to ensure that 144 the number of DFT points is sufficient. Thus, the original signal of tip force versus penetration 145 distance is padded with trailing zeros to increases its length, before computing the DFT.

146 Figure 6 presents one example of the amplitude spectrum when the $N$-points of DFT is equal to

1471,4 and 16 times respectively the number of data of the signal detected between $s=0$ and $148 s=s_{\max }$ for one impact in the material $A$. We found that the amplitude spectrum becomes stable 149 when $N$-points DFT increases.

150 Figure 7 presents two examples of amplitude spectrum related to the materials $A$ and $C$ 151 corresponding respectively to maximal and minimal average particle diameters. The first part 152 of the spectrum i.e. $f_{k}<100\left[\mathrm{~m}^{-1}\right]$ corresponds to a transition zone where amplitude spectrum 153 decreases rapidly. Thus, we introduce one parameter called $\left(f_{\text {trans }}\right)$ which is the frequency 154 corresponding to the first local minimum value of the amplitude spectrum (Fig.6).

155 In order to analyze the oscillations of the load-penetration curves, we studied the range of 156 frequencies that provides the most significant information to rebuild the signal with inverse 157 DFT and to filter the signal noise. For that purpose, the relative error RE between the 158 reconstructed signal of the $k$ first components $\left(y_{k}\right)$ based on Eq. 3 and the original signal (y) 159 descripted by the following equation has been computed.

$$
R E=\frac{\sum_{1}^{N}\left\|y^{i}-y_{k=0: i}^{i}\right\| \times\left(x^{i}-x^{i-1}\right)}{\sum_{i}^{N} y^{i} \times\left(x^{i}-x^{i-1}\right)}
$$

160 Figure 8 presents the relative error $(R E)$ for one impact of the material $A$. The range of 161 frequencies $\left[0, f_{\text {limit }}\right]$ that gives an RE smaller than $10 \%$ was chosen for rebuilding the signal 162 and for the load-penetration curves analysis. Note that, the more RE decreases, the more the reconstructed signal is accurate in comparison to the raw signal.

164 Figure 9 presents one example of signal reconstruction for the material $A$. We found that the 165 signal reconstructed with the frequency range $\left[0, f_{\text {trans }}\right]$ provides the general trend (baseline) of 166 the load-penetration curve. The signal reconstructed with the frequency range $\left[0, f_{\text {limit }}\right]$ provides 167 a reliable reconstruction of the raw signal without noise. Thus, we define the band-pass of 
168 frequency (BF range) from $f_{\text {trans }}$ to $f_{\text {limit }}$, for obtaining the full oscillation information of load169 penetration curve. The reconstructed signal with $\left[f_{\text {trans }}, f_{\text {limit }}\right]$ frequency range presents the major oscillations of load-penetration curve.

\section{Effect of PSD variation}

172 The effect of PSD on the load-penetration curve in terms of tip resistance $\left\langle R_{d}\right\rangle$ and in frequency 173 domain by using the frequencies detected in band-pass range $\left[f_{\text {trans }}, f_{\text {limit }}\right]$ is presented in this section. The PSD types I and II are studied in this section (Tab.2).

175 Figure 10 presents the load-penetration curves of 5 impacts for materials $\mathrm{A}, \mathrm{B}$ and $\mathrm{C}$. These materials have the same ratio $D_{\max } / D_{\min }=2$ and $D_{50}$ of respectively $7.02 \mathrm{~mm}, 3.51 \mathrm{~mm}$ and $1.76 \mathrm{~mm}$. Figure 11 presents the load-penetration curves of 5 successive impacts for the materials $\mathrm{A}, \mathrm{D}$ and $\mathrm{E}$. These materials have a ratio $D_{\max } / D_{\min }$ of respectively 2,5 and 10 , and the same maximal diameter $D_{\max }$ of $7.02 \mathrm{~mm}$. We found that the final penetration distance and the signals oscillations amplitude increases as $D_{50}$ decreases and $D_{\max } / D_{\min }$ ratio increases.

181 Concerning the macroscopic response, Figure 12 shows $\left\langle R_{d}\right\rangle$ as function of $D_{50}$ for the 5 different psd $A$ to $E$. In general, $\left\langle R_{d}\right\rangle$ increases when $D_{50}$ increases and the standard deviation decreases for smaller particles sizes. Thus, the response is more variable for coarser material. In addition, as $D_{\max } / D_{\min }$ increases, we found that $\left\langle R_{d}\right\rangle$ sightly decreases and that the standard deviation decreases. Thus, it seems that $\left\langle R_{d}\right\rangle$ decreases faster as function of $D_{50}$ than for the effect of spreading. As the quantity of smaller particles increases, the response given by the load-penetration curve is more repeatable.

188 The oscillations of the load-penetration curve vary as function of the combination of their frequencies $f_{k}$ and the associated amplitudes $A_{k}$. We can observe on the load-penetration curves of Fig.10 and 11 than the amplitudes of oscillations decrease and the frequency increases as the material becomes finer. It is then more difficult to detect the frequency features for finer materials i.e $C$ or $E$.

193 In order to quantify the oscillations of the load-penetration curve for each material and in order

194 to compare them to each other, we defined the coefficient $A f$ as the average value of the product 195 of the frequency $f_{k}$ and the associated amplitude $A_{k}$ detected in the band-pass range $\left[f_{\text {trans, }} f_{\text {limit }}\right]$.

$$
A f=\frac{\sum_{k=1}^{n} A_{k} \times f_{k}}{n}
$$

196 with $n$ the number of frequencies detected in band-pass range $\left[f_{\text {trans }}, f_{\text {limit }}\right]$. 
Figure 13 presents the coefficient $A f$ averaged on 15 impacts for each material $A$ to $E$ as function

198 of $D_{50}$ and of PSD spreading. We found that $\langle A f\rangle$ and its standard deviation decrease as the average diameter $D_{50}$ decreases. The coefficient $\langle A f\rangle$ was also found to decrease as the spreading of PSD increases. It means that the oscillations of load-penetration curve, quantified by a coefficient $\langle A f\rangle$, are dependent on the PSD of the material tested.

\section{Conclusions}

203

In this paper, we presented a method to analyze the dynamic penetration test results, based on the Discrete Fourier Transform. This method was used on results of dynamic penetration test of Panda modelled in 2D with DEM. The method was applied to the evaluation of the variation of particle size distribution of a coarse granular material, on and more particularly the influence of average particle diameter and particle size distribution span. Five different materials were simulated under dynamic penetration test.

The discrete Fourier transform was applied on the load vs. penetration curves so that:

- the oscillations of the penetration curve can be reconstructed

- a band-pass range that characterizes the material in terms of particle size distribution can be identified

- influence of mean diameter $D_{50}$ on the both global response and signal oscillations can be quantified with a scalar called here amplitude coefficient $\langle A f\rangle$ calculated from the frequencies and associated amplitudes in the characteristic band-pass range. This coefficient captures only the nature of the oscillations and is influenced by particle size distribution of the material.

Concerning the macroscopic response, we observed that

- average tip resistance decreases when the content of smaller particles increases: when $D_{50}$ decreases and when the spreading of the particle size distribution increases

- the DFT applied on signal obtained with finer granular materials shows a distribution of frequencies and associated amplitude that is more flat, in the characteristic band-pass range, making it more difficult to detect the characteristic frequency and amplitude of the oscillations for such materials.

The method presented in this paper based on spectral analysis will be useful to extract more information from the penetrometer test results, in terms of physical properties of the material, and beyond the classical tip resistance. Further investigations using three-dimensional modeling 
228 and experimental validation will have to be performed in order to confirm and extend the 229 benefits of this method. 
[1] Chaigneau, L.: Caractérisation des milieux granulaires de surface à l'aide d'un

[2] Breul, P., Benz, M., Gourvès, R., Saussine, G.: Penetration Test Modelling in a Coarse Granular Medium. In Powders and Grains 2009: Proceedings of the $6^{\text {th }}$ International Conference on Micromechanics of Granular Media, 1145(1), pp.173-176, AIP Publishing (2009)

[3] Benz Navarrete, M.: Mesures dynamiques lors du battage du pénétromètre Panda 2. $\mathrm{PhD}$ thesis, Clermont-Ferrand: Université Blaise Pascal (2009)

[4] Escobar E., Benz Navarrete M., Gourvès R., Haddani Y., Breul P., Chevalier B.: Dynamic Characterization of the Supporting Layers in Railway Tracks Using the Dynamic Penetrometer Panda 3®, Procedia Engineering, 143, (2016) 1024-1033

http://dx.doi.org/10.1016/j.proeng.2016.06.099.

[5] Benz, M.A., Escobar, E., Gourvès, R., Haddani, Y., Breul, P. Bacconnet, C. Dynamic measurements of the penetration test - Determination of the tip's dynamic load penetration curve. Proc. of the 18th Int. Conf. on the Soil Mech. and Geotech. Eng., Paris, pp.499-502 (2013)

[6] Escobar Valencia E.J.: Mise au point et exploitation d'une nouvelle technique pour la reconnaisance des sols: le PANDA 3. PhD thesis, Clermont-Ferrand: Université Blaise Pascal (2015)

[7] Tran, Q.A., Chevalier, B., Breul, P.: Discrete modeling of penetration tests in constant velocity and impact conditions. Computers and Geotechnics, 71, 12-18 (2016)

[8] Huang A.B., Ma M.Y.: An analytical study of cone penetration test in granular material. Can Geotech J, 31(1), 91-103. (1994)

[9] Huang A.B., Hsu H.H.: Advanced calibration chambers for cone penetration testing in cohesionless soils. In: ISC-2 Geotech and Geophys Site Characterization, pp.147-66, Porto, (2004)

[10] Calvetti F., Nova R.: Micro-macro relationships from DEM simulated element and in-situ tests. In: Proc 5th Int Conf Micromech Granular Media: Powders and Grains 2005, Stuttgart, pp.245-250 (2005)

[11] Jiang M.J., Yu H.-S., Harris D.: Discrete element modeling of deep penetration in granular soils. Int J Numer Anal Meth Geomech, 30(4), 335-61 (2006)

[12] Jiang MJ, Harris D, Zhu H.: Future continuum models for granular materials in penetration analyses. Granular Matter, 9(1), 97-108. (2007)

[13] Jiang M, Dai Y, Cui L, Shen Z, Wang X.: Investigating mechanism of inclined CPT in granular ground using DEM. Granular Matter, 16(5), 785-96 (2014) 
[14] Tran Q.A., Chevalier B., Breul P.: A numerical study of the penetration test at constant rod velocity. In: Oka, Murakami, Uzuoka, Kimoto, editors. Computer methods methods and recent advances in geomechanics, pp. 193-8, Kyoto (2015)

[15] Janda, A., Ooi, J. Y.: DEM modeling of cone penetration and unconfined compression in cohesive solids. Powder Technology (2015). doi: 10.1016/j.powtec.2015.05.034

[16] Arroyo M., Butlanska J., Gens A., Calvetti F., Jamiolkowski M.: Cone penetration tests in a virtual calibration chamber. Géotechnique, 61(6), 525-31. (2011)

[17] Butlanska, J., O Sullivan C, Arroyo M., Gens A., Jiang M., Liu F. and Bolton M: Mapping deformation during CPT in a virtual calibration chamber, in Proceedings of the International Symposium on Geomechanics and Geotechnics: From Micro to Macro. Taylor \& Francis Group Eds., pp.559-564 (2011)

[18] McDowell G.R., Falagush O, Yu H.S.: A particle refinement method for simulating DEM of cone penetration testing in granular materials. Geotech Lett, 2, 141-7 (2012)

[19] Quezada, J.C., Breul, P., Saussine, G., Radjai, F.: Penetration test in coarse granular material using Contact Dynamics Method. Computers and Geotechnics, 55, 248-253 (2014)

[20] Ciantia, M.O., Arroyo, M., Butlanska, J., Gens, A.: DEM modelling of cone penetration tests in a double-porosity crushable granular material. Computers and Geotechnics, 73, 109127 (2016)

[21] Cundall P.A., Strack O.D.L.: A discrete numerical model for granular assemblies. Géotechnique, 29(1), 47-65 (1979)

[22] Combe G. Mécanique des matériaux granulaires et origines microscopiques de la déformation. Etudes et Recherches du Laboratoire Central des Ponts et Chaussées. SI8. (2002)

[23] Roux J.-N., Chevoir F.: Discrete numerical simulation and the mechanical behavior of granular materials. Bulletin du Laboratoire des Ponts et Chaussées, 254,109-138 (2005)

[24] Tran Q.A.: Modélisation numérique du comportement des milieux granulaires à partir de signaux pénétrométriques: approche micromécanique par la méthode des éléments discrets. $\mathrm{PhD}$ thesis , Université Blaise Pascal-Clermont-Ferrand II (2015) 
318 Table 1. Parameters of the model.

\begin{tabular}{lccc}
\hline Parameter & Symbol & Value & Unit \\
\hline Width box & $L$ & 0.60 & $\mathrm{~m}$ \\
Height box & $H$ & 0.45 & $\mathrm{~m}$ \\
Particle density & $\rho$ & 2700 & $\mathrm{~kg} \cdot \mathrm{m}^{-3}$ \\
Normal contact stiffness & $k_{n}$ & $1.25 \times 10^{8}$ & $\mathrm{~N} . \mathrm{m}^{-1}$ \\
Tangential contact stiffness & $k_{s}$ & $9.375 \times 10^{7}$ & $\mathrm{~N}^{-1}$ \\
Rod friction coefficient & $\mu_{\text {rod }}$ & 0.0 & - \\
Tip friction coefficient & $\mu_{\text {tip }}$ & 0.3 & - \\
\hline
\end{tabular}


320 Table 2. Material characteristics used in penetration tests with different particle size 321 distribution.

\begin{tabular}{|l|c|c|c|c|c|c|}
\hline Ref & $\begin{array}{c}\text { Particle number } \\
\mathbf{N}_{\mathbf{p}}\end{array}$ & $\phi_{\max }[-]$ & $\mathbf{D}_{\max }[\mathbf{m m}]$ & $\mathbf{D}_{\text {50 }}[\mathbf{m m}]$ & $\mathbf{D}_{\mathbf{m a x}} / \mathbf{D}_{\min }[-]$ & Type \\
\hline A & 10000 & 0.844 & 7.02 & 5.80 & 2 & I;II \\
\hline B & 40000 & 0.843 & 3.51 & 2.91 & 2 & I \\
\hline C & 160000 & 0.843 & 1.76 & 1.45 & 2 & I \\
\hline D & 30000 & 0.856 & 7.02 & 3.98 & 5 & II \\
\hline E & 97831 & 0.869 & 7.02 & 2.61 & 10 & II \\
\hline
\end{tabular}


325 Figure 1. Experimental result of dynamic penetration test [12]

326 Figure 2. Example of experimental load-penetration curve obtained in a dynamic penetration test for 327 one impact [3]

328 Figure 3. View of the numerical model of the tip and of the container for the penetration test in

329 dynamic conditions (Tran et al., 2015)

330 Figure 4. Particle size distribution (a) for different average particle diameters (materials A, B and C) 331 and (b) for different particle size distribution shapes (materials A, D and E)

332 Figure 5. Example of load-penetration curves obtained in a dynamic cone penetration test for 3

333 impacts in material A

334 Figure 6. Example of the amplitude spectrum of one impact of the material $A$ with different numbers 335 of $N$-points DFT

336 Figure 7. Example of the amplitude spectrum of five impacts for two materials $A$ and $C$

337 Figure 8. Relative error for one impact of the material $A$

338 Figure 9. (Left) Comparison of the raw load-penetration curve for the material $A$ with signal 339 reconstructed with frequency ranges $\left[0, f_{\text {trans }}\right]$ and $\left[0, f_{\text {limited }}\right]$. (Right) Signal reconstructed with

340 frequency range $\left[f_{\text {trans }}, f_{\text {limited }}\right]$ showing the major oscillations of load-penetration curve

341 Figure 10. Tip force as a function of penetration distance for 5 successive dynamic penetration tests 342 for materials A, B and C

343 Figure 11. Tip force as a function of penetration distance for 5 successive dynamic penetration tests 344 for materials A, D and E

345 Figure 12. (Left) $\left\langle R_{d}\right\rangle$ as function of $D_{50}$ with five PSD A to E. (Right) $\left\langle R_{d}\right\rangle$ as function of PSD shape 346 for three materials $\mathrm{A}, \mathrm{D}$ and $\mathrm{E}$ (height of vertical bars is twice the standard deviation of $R_{d}$ )

347 Figure 13. (Left) $\langle A f\rangle$ as fonction of $D_{50}$ for five particle size distributions A to E. (Right) $\langle A f\rangle$ as 348 function of psd shape for three particle size distributions A, D and E (height of vertical bars represent 349 twice the standard deviation of $\langle A f>$ ) 
Figure 1. Experimental result of dynamic penetration test [12]

Figure 2. Example of experimental load-penetration curve obtained in a dynamic penetration test for one impact [3]

Figure 3. View of the numerical model of the tip and of the container for the penetration test in dynamic conditions (Tran et al., 2015)

Figure 4. Particle size distribution (a) for different average particle diameters (materials A, B and C) and (b) for different particle size distribution shapes (materials A, D and E)

Figure 5. Example of load-penetration curves obtained in a dynamic cone penetration test for 3 impacts in material A

Figure 6. Example of the amplitude spectrum of one impact of the material $A$ with different numbers of $N$-points DFT

Figure 7. Example of the amplitude spectrum of five impacts for two materials $A$ and $C$

Figure 8. Relative error for one impact of the material $A$

Figure 9. (Left) Comparison of the raw load-penetration curve for the material $A$ with signal reconstructed with frequency ranges $\left[0, f_{\text {trans }}\right]$ and $\left[0, f_{\text {limited }}\right]$. (Right) Signal reconstructed with frequency range $\left[f_{\text {trans }}, f_{\text {limited }}\right]$ showing the major oscillations of load-penetration curve

Figure 10. Tip force as a function of penetration distance for 5 successive dynamic penetration tests for materials $\mathrm{A}, \mathrm{B}$ and $\mathrm{C}$

Figure 11. Tip force as a function of penetration distance for 5 successive dynamic penetration tests for materials A, D and $\mathrm{E}$

Figure 12. (Left) $\left\langle R_{d}\right\rangle$ as function of $D_{50}$ with five PSD A to E. (Right) $\left\langle R_{d}\right\rangle$ as function of PSD shape for three materials $\mathrm{A}, \mathrm{D}$ and $\mathrm{E}$ (height of vertical bars is twice the standard deviation of $R_{d}$ )

Figure 13. (Left) $\langle A f\rangle$ as fonction of $D_{50}$ for five particle size distributions A to E. (Right) $\langle A f\rangle$ as function of psd shape for three particle size distributions A, D and E (height of vertical bars represent twice the standard deviation of $\langle A f>$ ) 


\section{Tip resistance [MPa]}

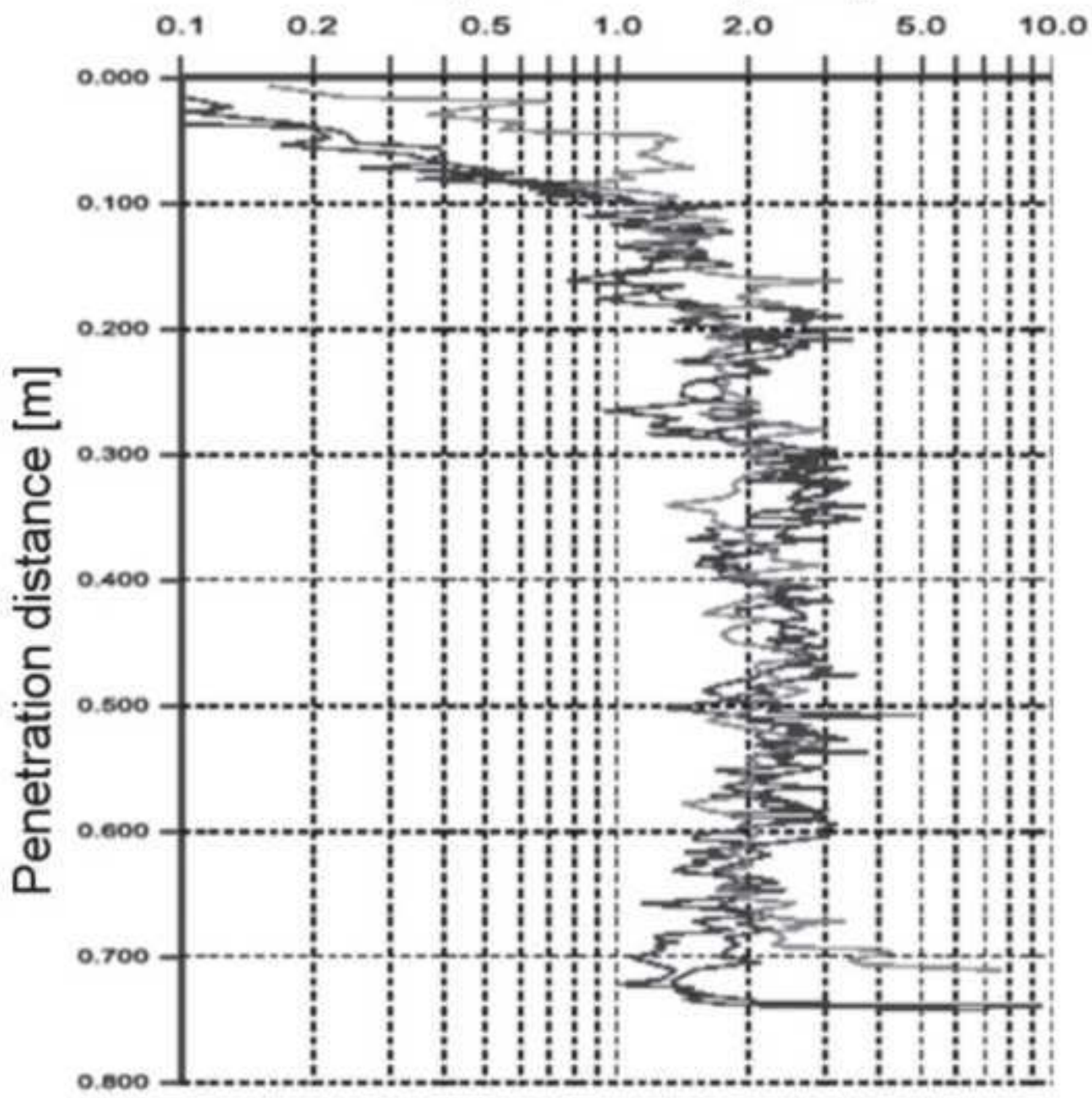




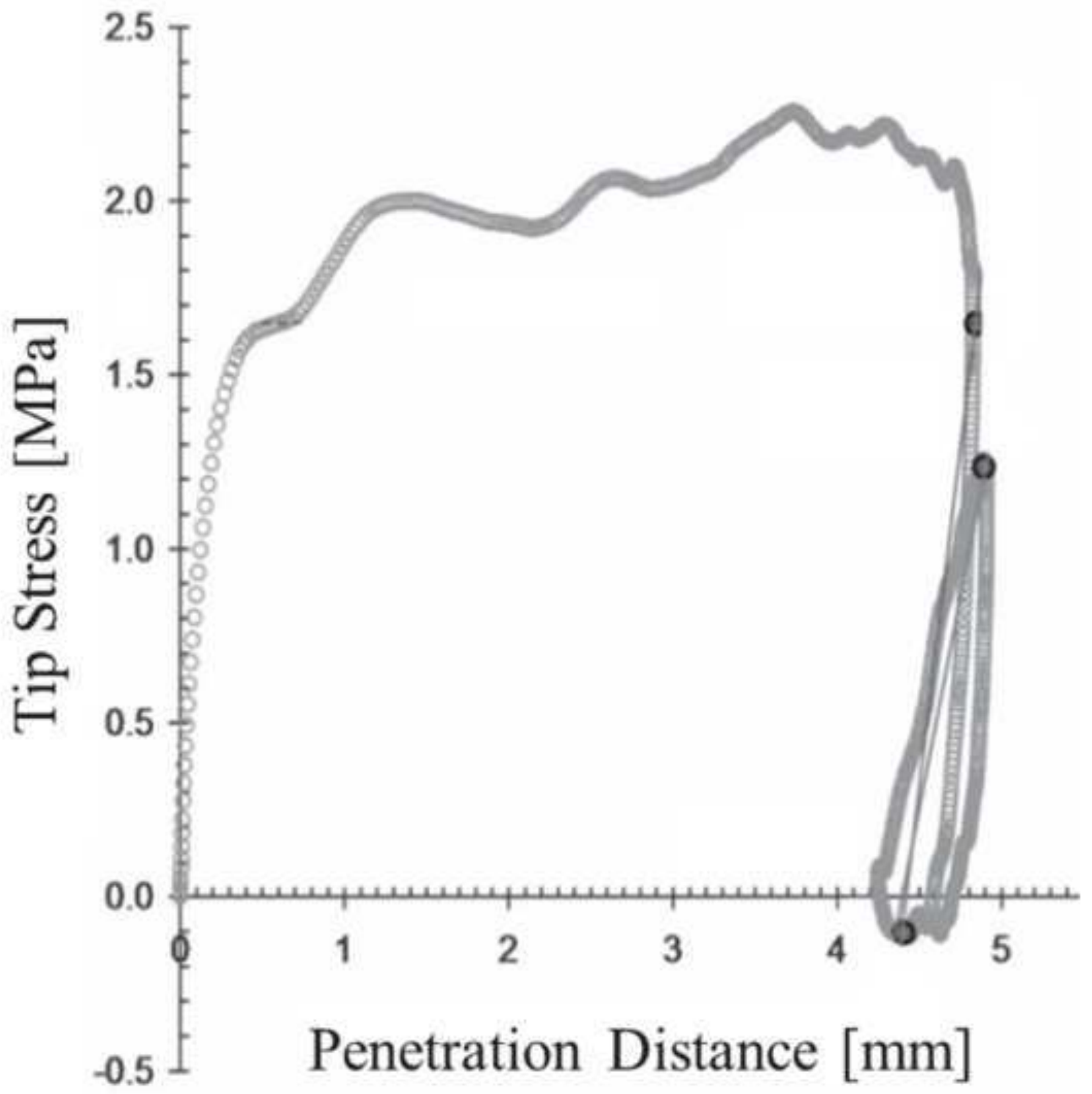



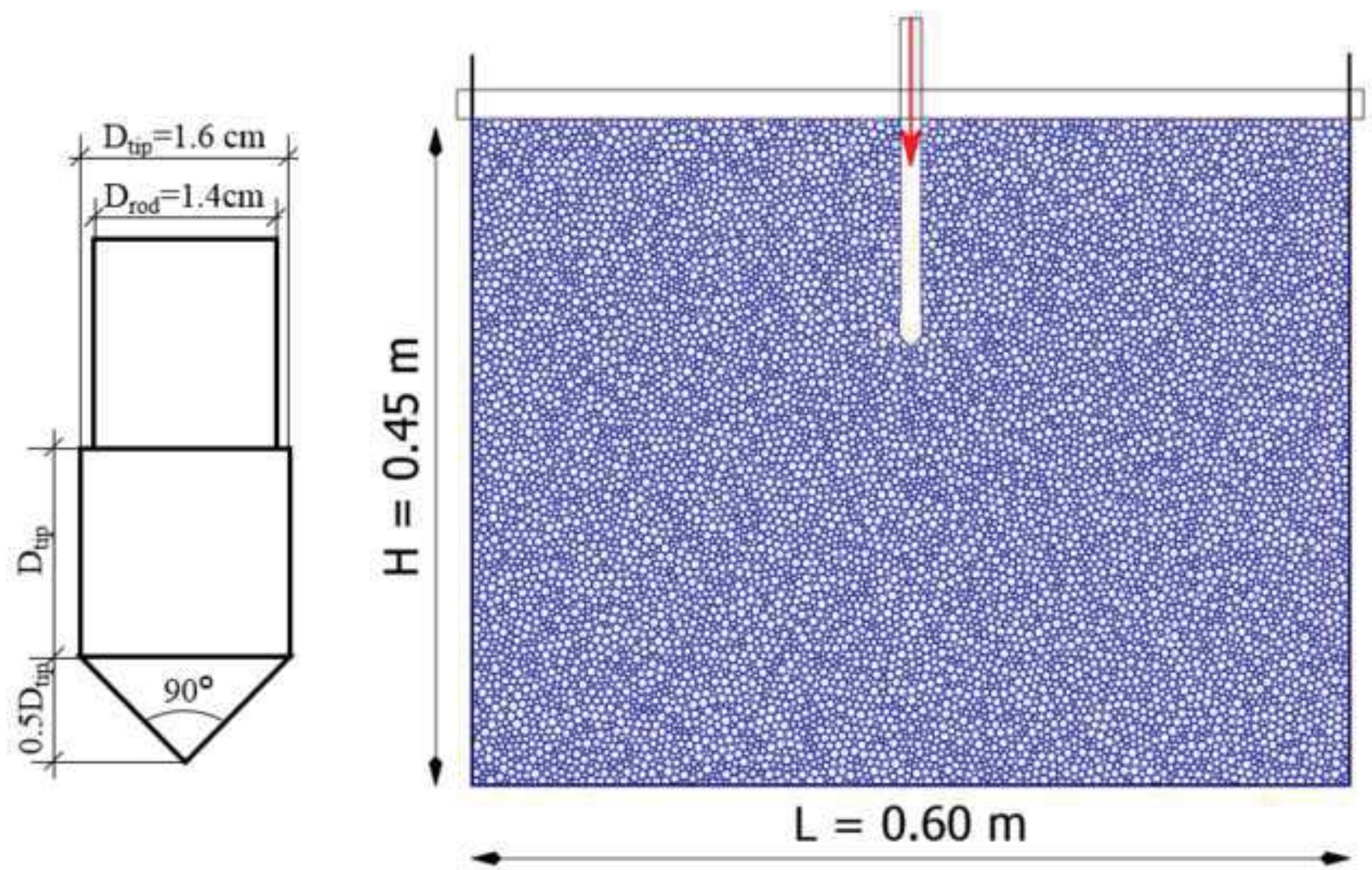

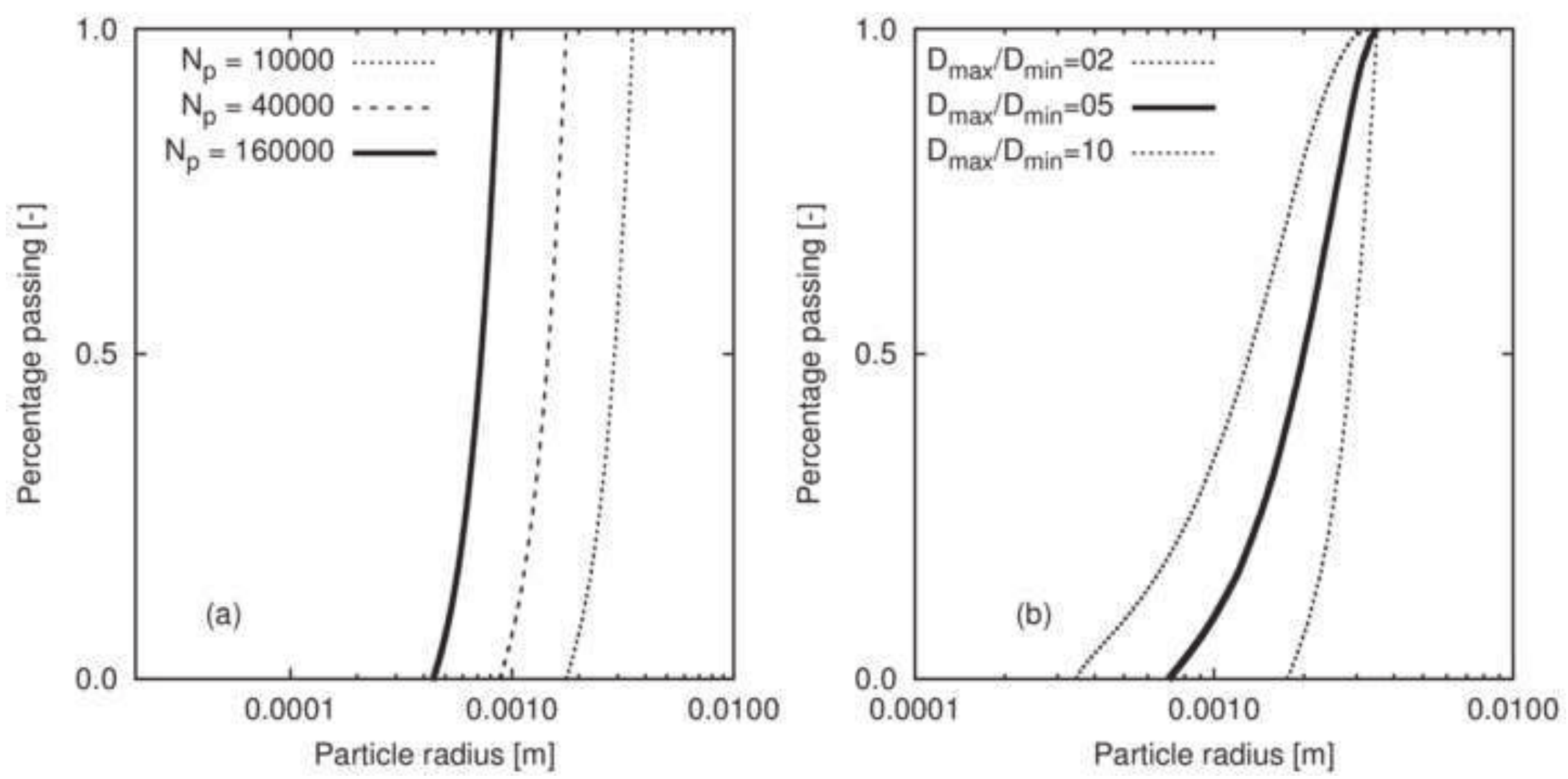


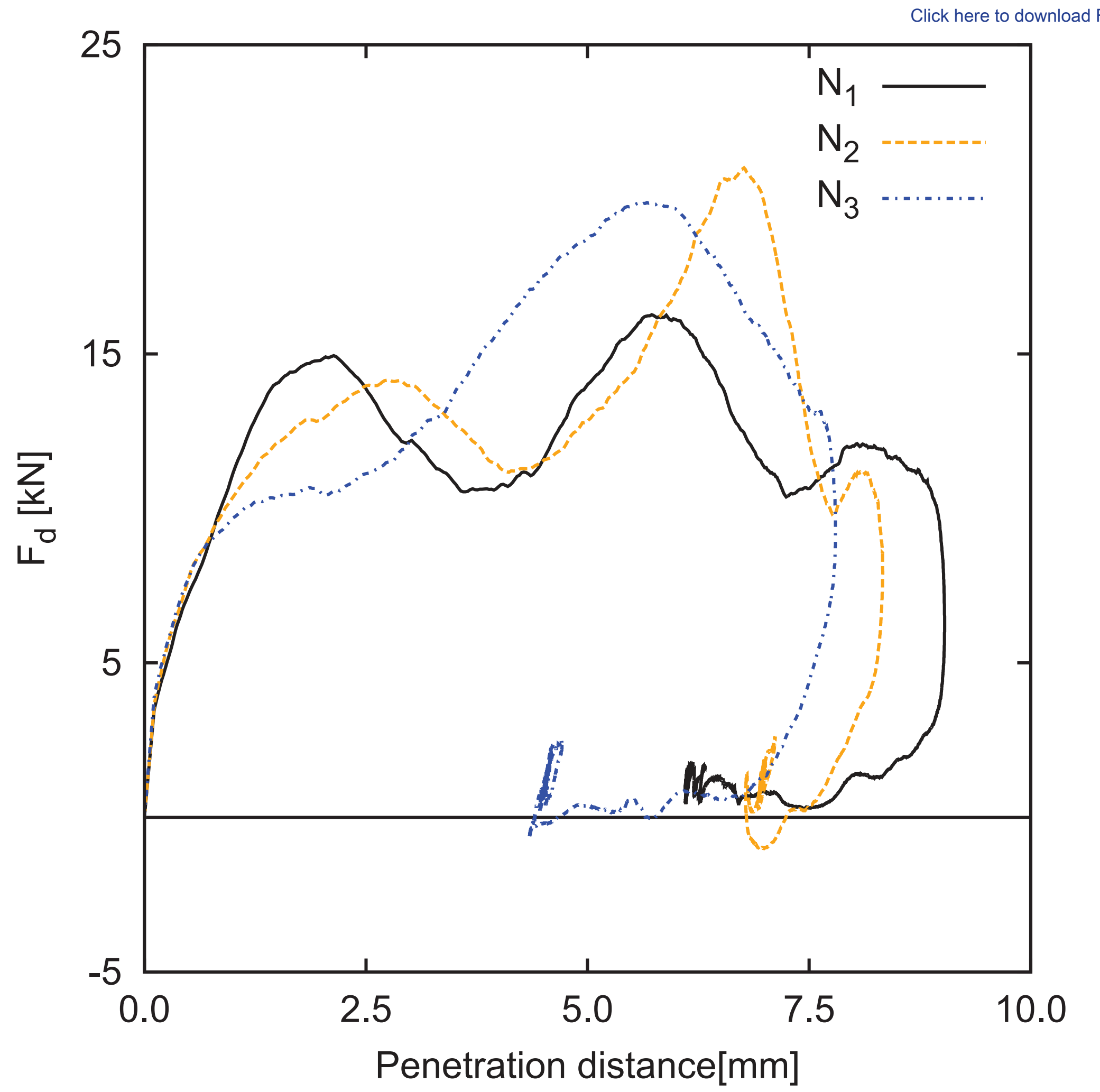




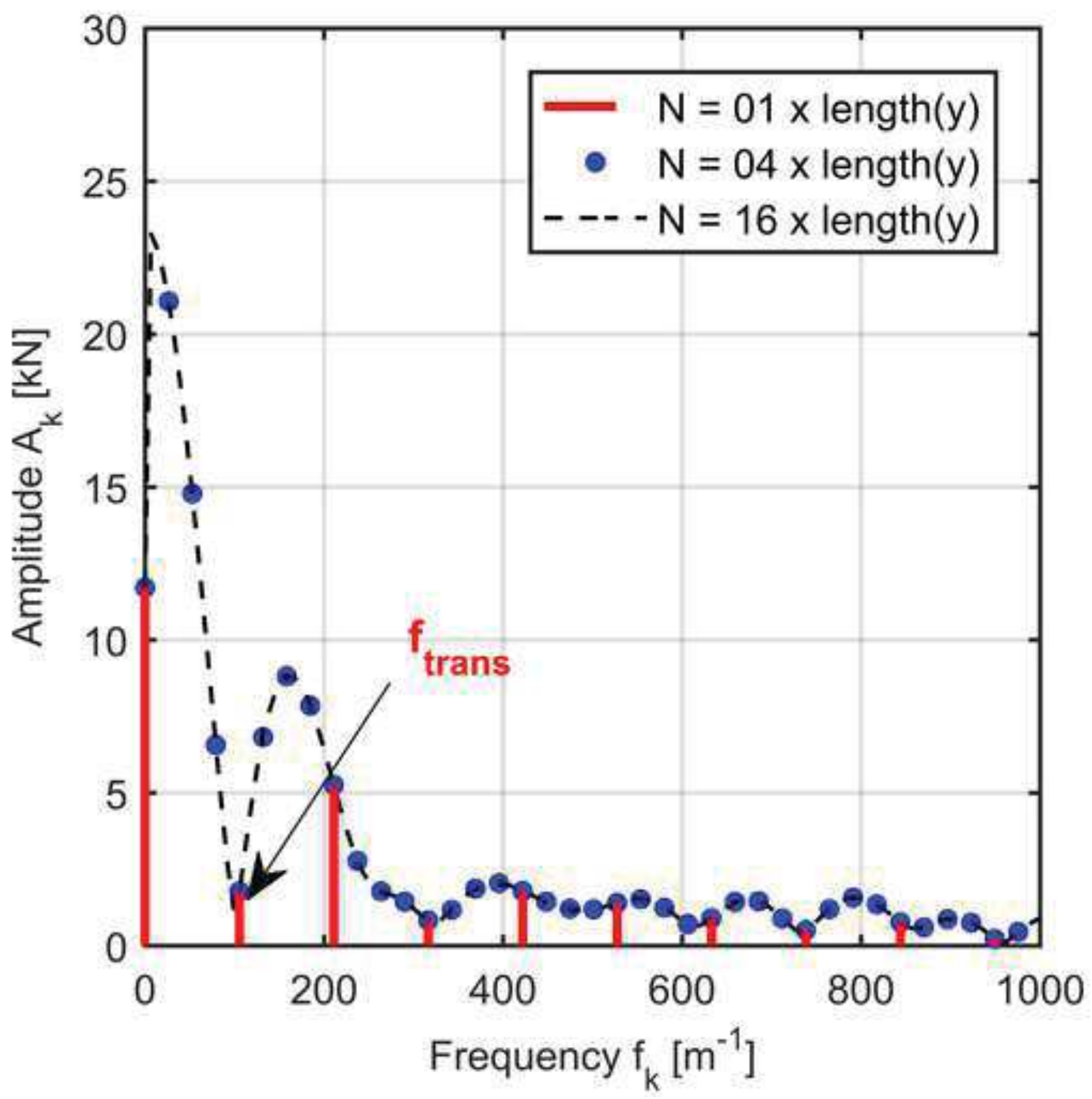



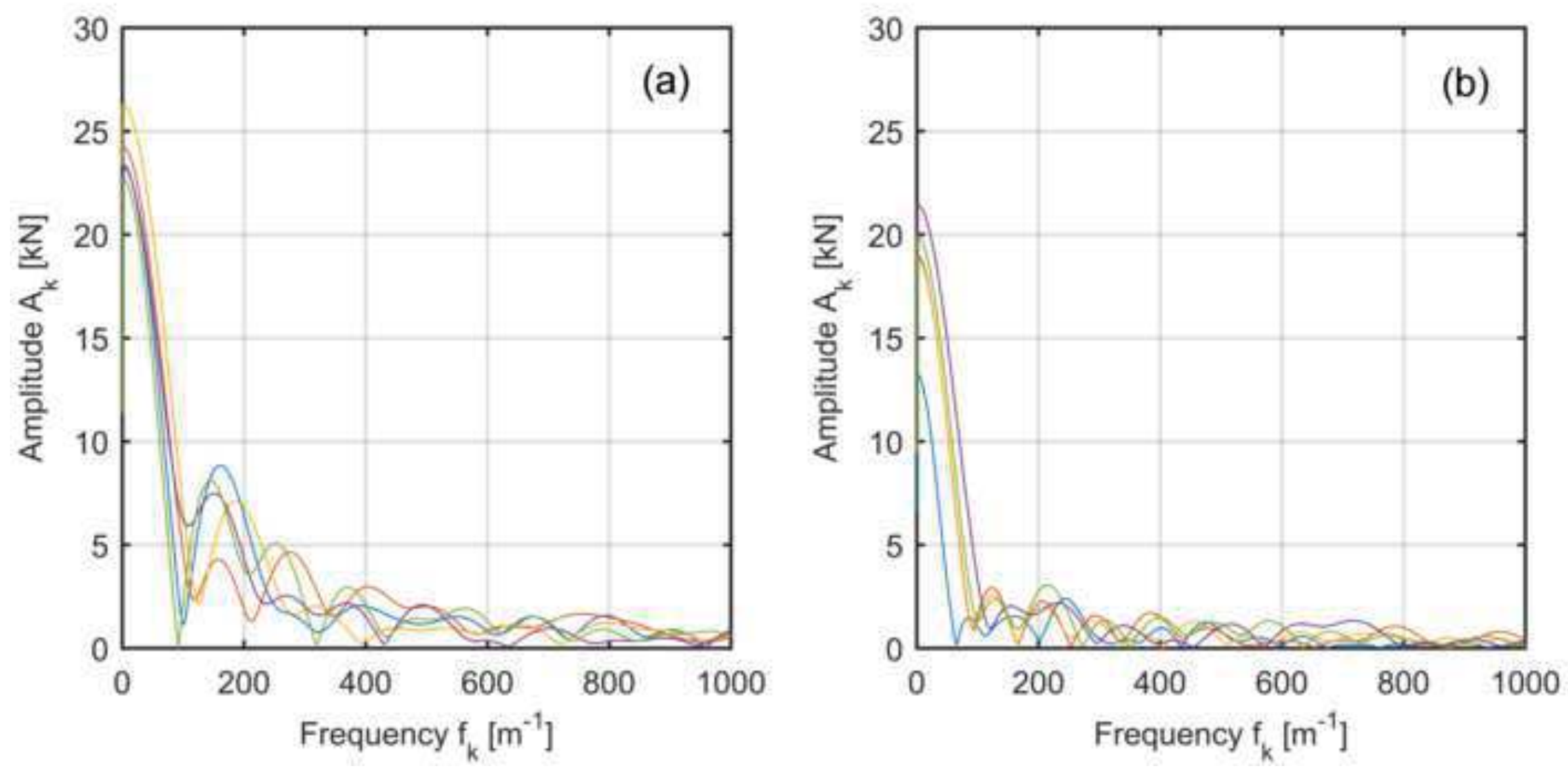


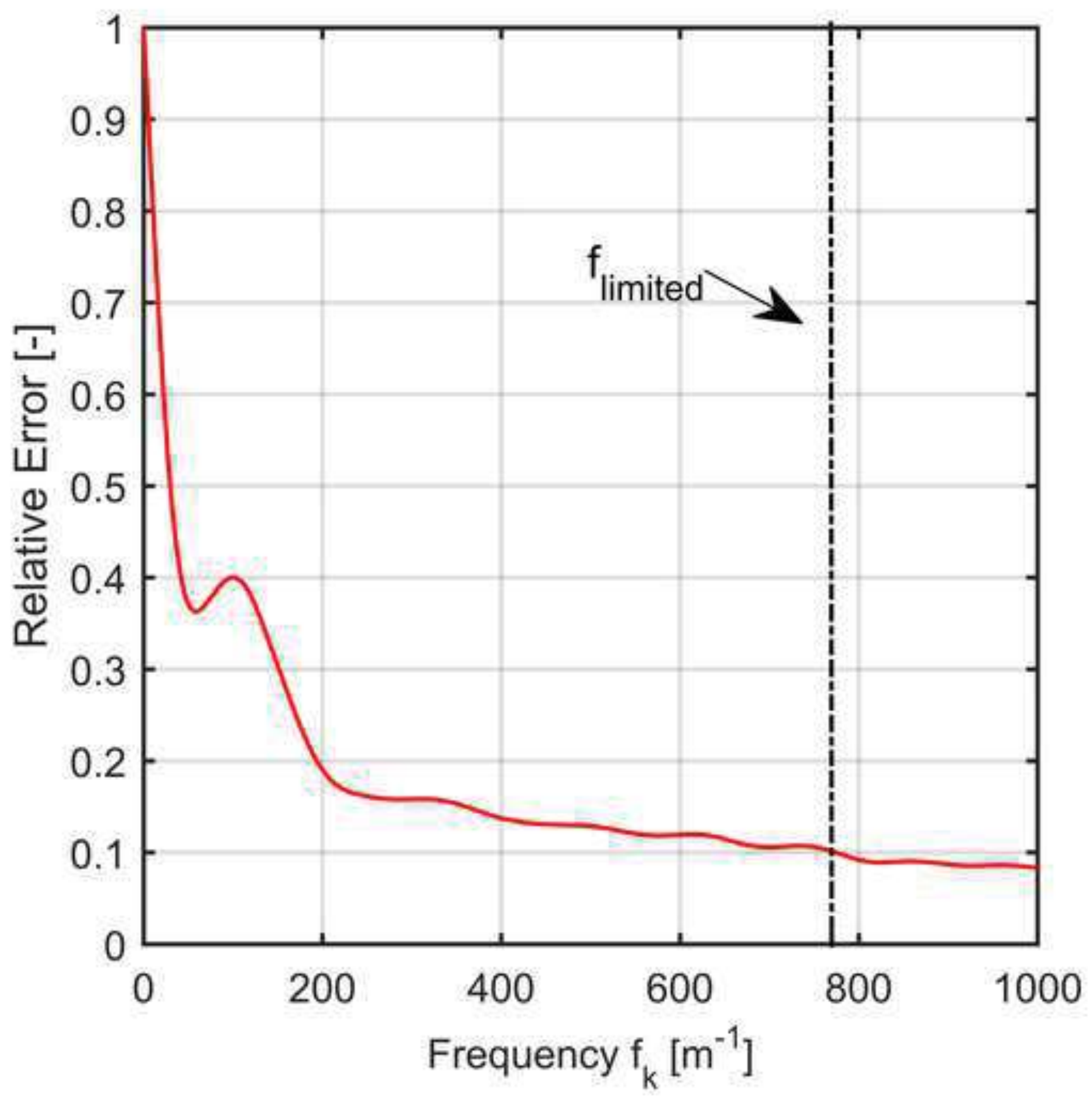



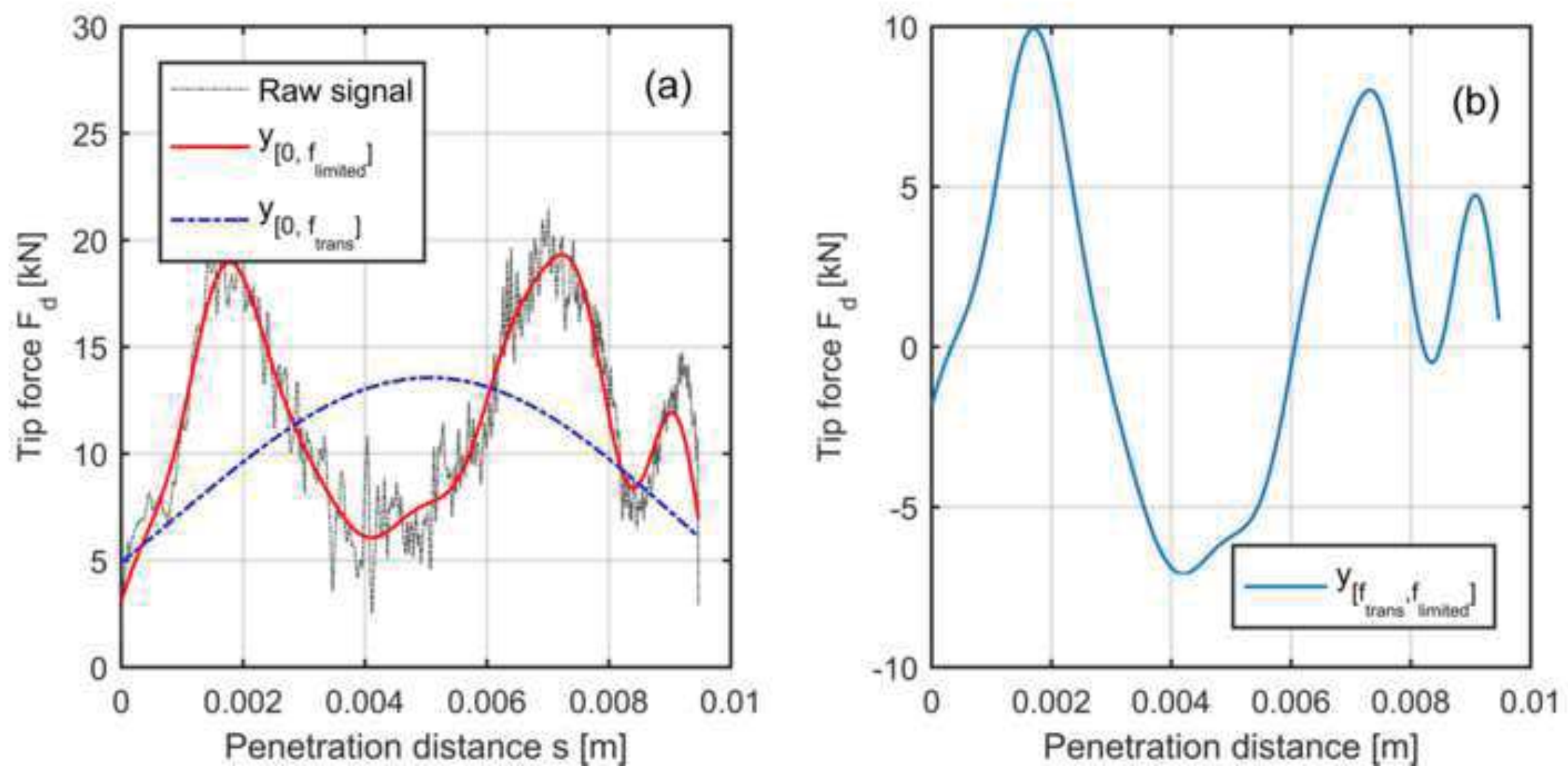

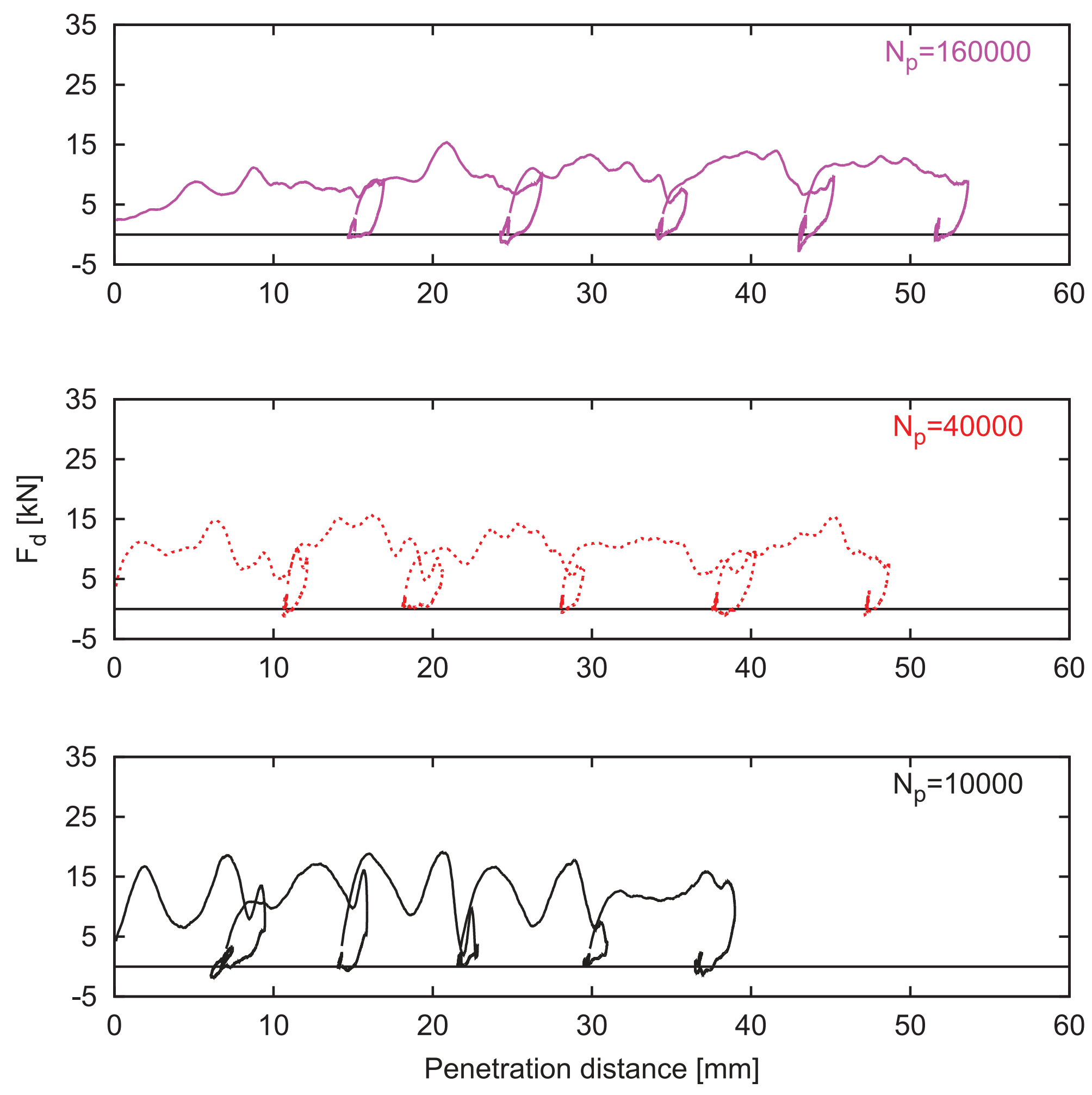

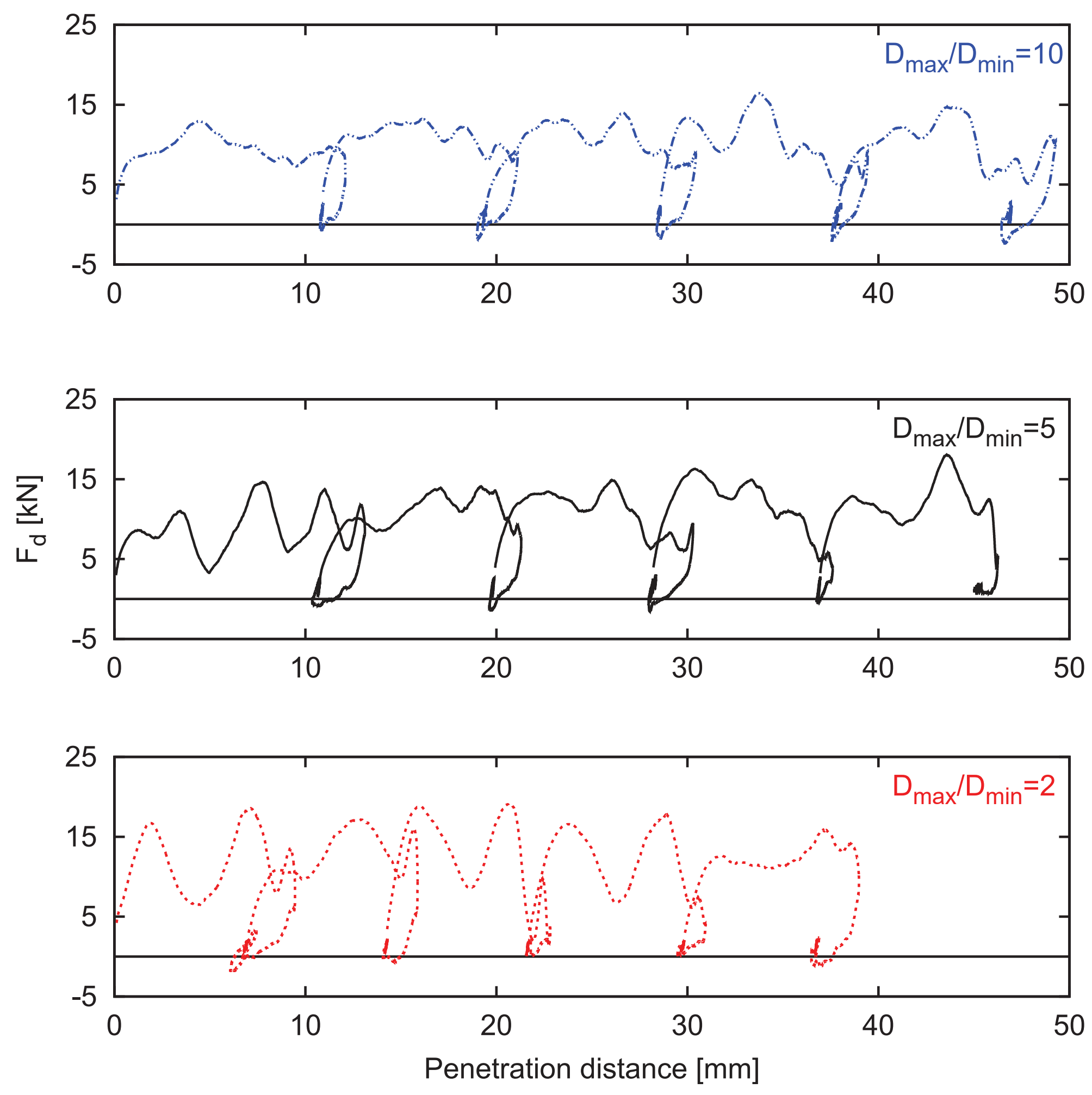

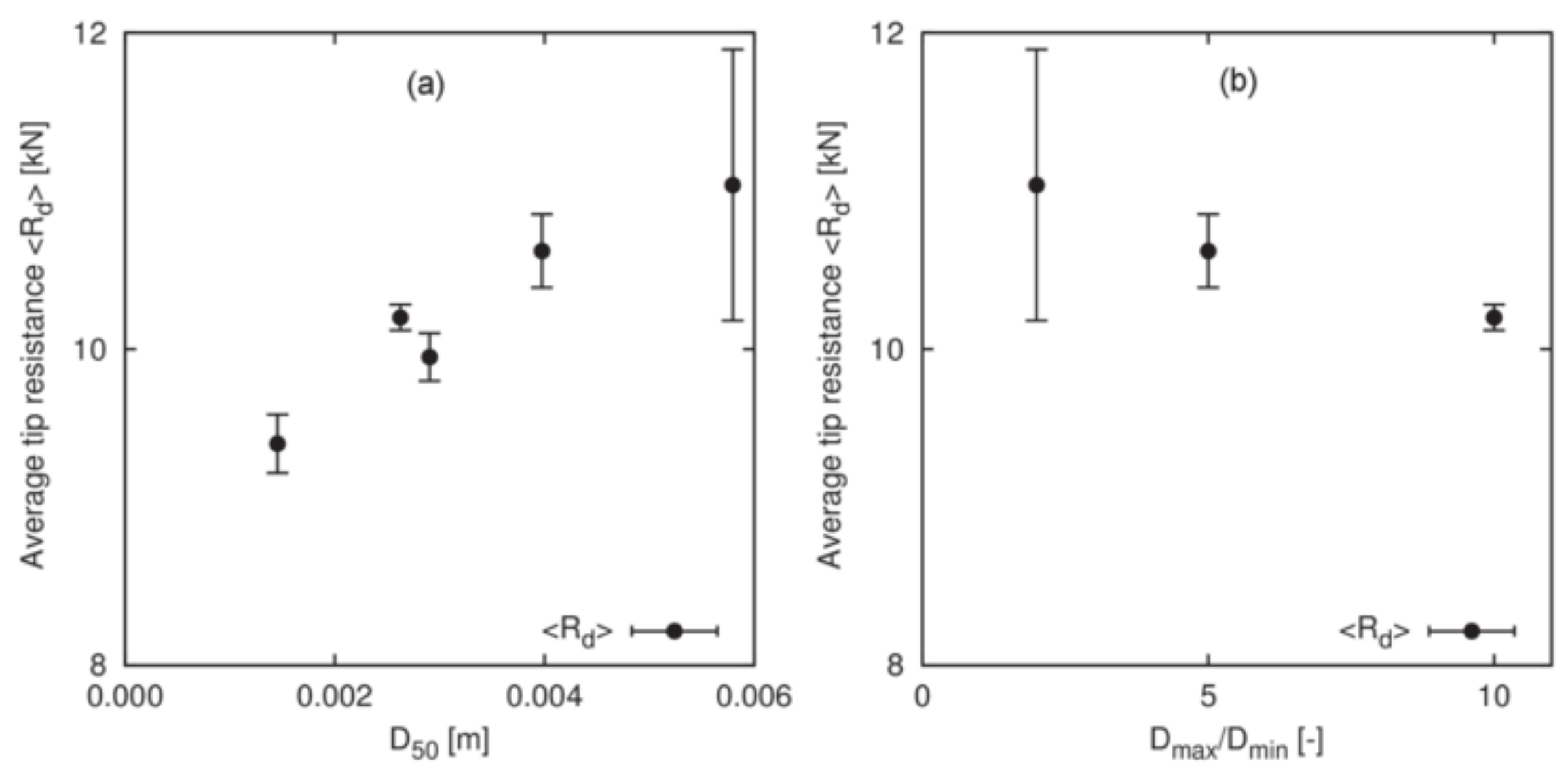

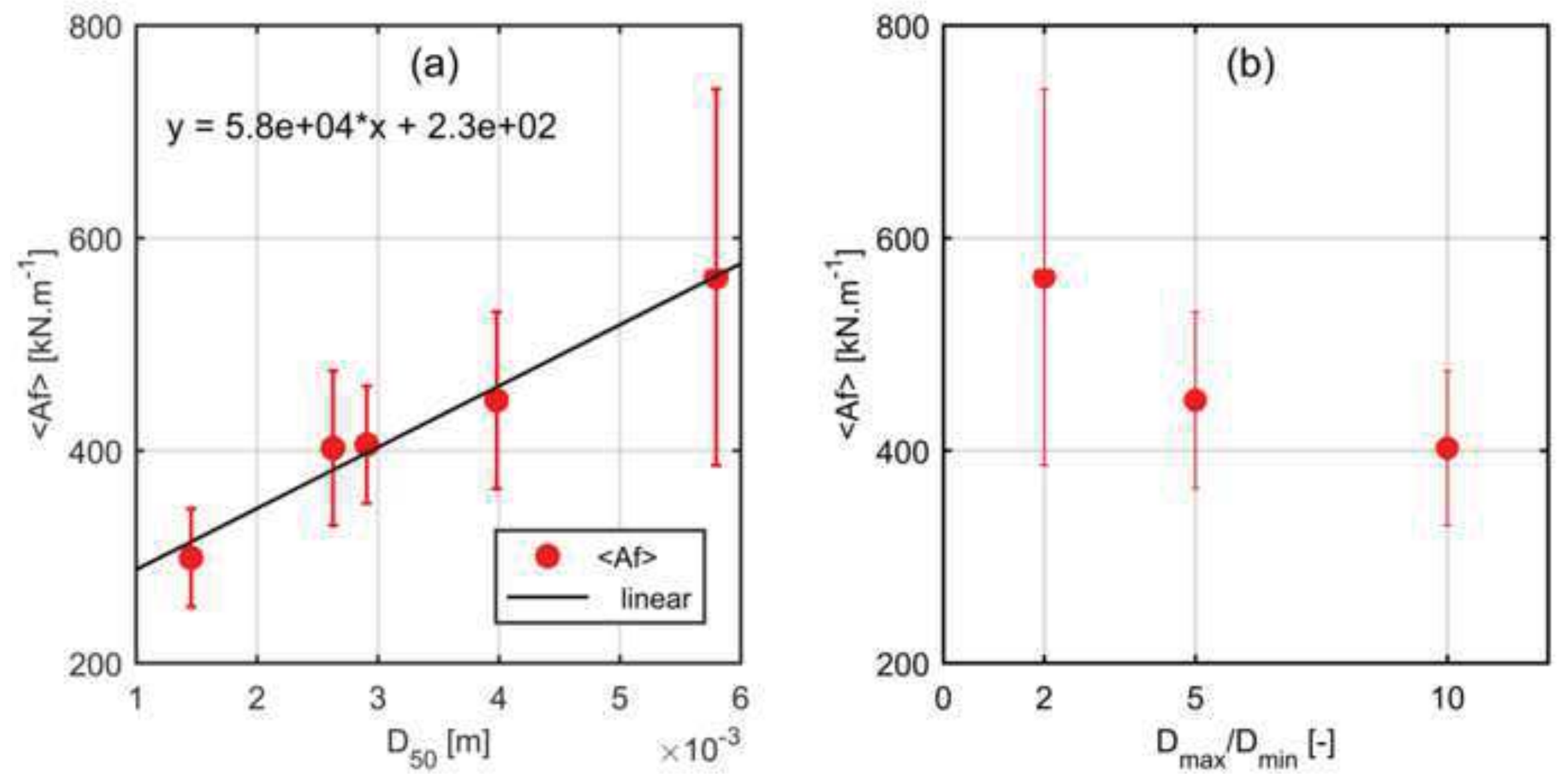